\title{
Early coagulopathy in children with isolated blunt head injury is associated with mortality and poor neurological outcomes
}

\author{
Vigil James, MRCPCH, Shu-Ling Chong, MPH, Shanti S. Shetty, MBBS, and \\ Gene Y. Ong, MRCPCH \\ Children's Emergency, KK Women's and Children's Hospital, Singapore
}

\begin{abstract}
OBJECTIVE Traumatic brain injury (TBI) is the leading cause of long-term disability and death in children and adolescents globally. Long-term adverse outcomes, including physical, cognitive, and behavioral sequelae, have been reported after TBI in a significant number of pediatric patients. In this study the authors sought to investigate the epidemiology of TBI-associated coagulopathy and its association with mortality and poor neurological outcome in a pediatric population with isolated moderate to severe blunt head injury treated at the authors' institution.
\end{abstract}

METHODS This retrospective study was conducted in the children's emergency department between January 2010 and December 2016. Children $<18$ years old who presented with isolated moderate to severe blunt head injury were included in the study. The authors collected data on patient demographics, clinical presentation, and TBI management. Outcomes studied were death and poor neurological outcome defined by a score of $<7$ (death, moderate to severe neurological disability) at 6 months postinjury on the pediatric version of the Glasgow Outcome Scale-Extended (GOS-E Peds).

RESULTS In 155 pediatric patients who presented with isolated moderate to severe blunt head injury, early coagulopathy was observed in $33(21.3 \%)$ patients during the initial blood investigations done in the emergency department. The mean (SD) age of the study group was $7.03(5.08)$ years and the predominant mechanism of injury was fall from height $(65.2 \%)$. The median Abbreviated Injury Scale of the head (AIS head) score was 4 and the median GCS score was 13 (IQR 12-15). TBI-associated coagulopathy was independently associated with GOS-E Peds score $<7(p=0.02$, adjusted OR $6.07,95 \% \mathrm{Cl} 1.32-27.83$ ). The overall mortality rate was $5.8 \%$. After adjusting for confounders, only AIS head score and hypotension at triage remained significantly associated with TBI-associated coagulopathy.

CONCLUSIONS TBI-associated coagulopathy was independently associated with GOS-E Peds score $<7$ at 6 months postinjury. Larger prospective studies are needed to investigate the use of TBI-associated coagulopathy to prognosticate these critical clinical outcomes.

https://thejns.org/doi/abs/10.3171/2019.12.PEDS19531

KEYWORDS isolated head injury; pediatric; coagulopathy; neurological outcome; mortality publishing; style; guidelines; trauma

$\mathrm{T}$ RAUMATIC brain injury (TBI) is the leading global cause of long-term disability and death in children and adolescents. ${ }^{8,16}$ Long-term physical, cognitive, and behavioral sequelae have been reported in a significant number of pediatric patients after moderate to severe TBI. ${ }^{17,23}$

Early coagulopathy associated with isolated TBI is prognostic for longer ICU stay and increased mortality in adults. ${ }^{4,6,10,13,16,20}$ The risk factors for acquired coagulopathy associated with isolated head injuries include a
Glasgow Coma Scale (GCS) score of 8 or less, penetrating head trauma, ${ }^{11}$ and the presence of hypotension on admission. ${ }^{1,28}$ Various mechanisms leading to hypocoagulability have been proposed to explain the pathogenesis of primary coagulopathy in isolated TBI, including hypothesized tissue factor release, protein $\mathrm{C}$ pathway activation, thrombocytopenia, and platelet dysfunction. ${ }^{7,9,18,25,32,33}$ The incidence of and mechanisms resulting in acute coagulopathy differ between coagulopathies associated with penetrating injuries versus blunt head injuries..$^{10,28}$

ABBREVIATIONS AIS head = Abbreviated Injury Scale of the head; aPTT = activated partial thromboplastin time; ED = emergency department; GCS = Glasgow Coma Scale; GOS-E Peds = pediatric version of the Glasgow Outcome Scale-Extended; INR = international normalized ratio; MVC = motor vehicle collision; NAI = nonaccidental injury; $\mathrm{PT}=$ prothrombin time; $\mathrm{TBI}$ = traumatic brain injury.

SUBMITTED September 12, 2019. ACCEPTED December 30, 2019.

INCLUDE WHEN CITING Published online March 6, 2020; DOI: 10.3171/2019.12.PEDS19531. 
The association of coagulopathy with isolated TBI is an evolving concept in the treatment of pediatric patients, with limited available published literature on this topic. With the exception of a small observational study $(\mathrm{n}=$ 66), ${ }^{22}$ other reported studies on TBI-associated coagulopathy in the pediatric population used in-hospital outcome measures like death and ICU stay and did not address neurological outcomes, which is the critical focus of management for survivors with moderate to severe TBI. 3,21,25,28,29

\section{Study Goals}

In view of limited studies in the pediatric population, we set out to determine the epidemiology of TBI-associated coagulopathy in patients who presented to our emergency department (ED) with isolated moderate to severe blunt head injury and to study the relationship between coagulopathy and clinical outcomes of mortality and neurological outcomes in this cohort.

Secondary objectives of this study were to investigate associations between TBI-associated coagulopathy, indicators of patient condition at ED clinical presentation (specifically triage GCS score, hemodynamic status at triage, and initial neuroimaging findings), and subsequent critical management and interventions.

We hypothesized that TBI-associated coagulopathy in the pediatric age group is common and has prognostic value for mortality and long-term neurological outcomes.

\section{Methods}

\section{Study Design and Setting}

This was a retrospective study that included children younger than 18 years who presented to the KK Women's and Children's Hospital's Children's Emergency in Singapore between January 2010 and December 2016 after an isolated blunt head injury. Data prospectively collected by our hospital's pediatric trauma coordinator were obtained from our unit's pediatric head injury surveillance database and the institution's pediatric trauma.

\section{Selection of Participants}

Pediatric patients were included based on both of the following criteria: 1) traumatic blunt head injury with an Abbreviated Injury Scale of the head (AIS head) score of 3 or more and 2) all other body organ systems with an AIS score of less than 3. Based on current literature, that mortality and neurological outcomes of penetrating and blunt head injuries are significantly different, ${ }^{11,24}$ we did not want to confound results by including both penetrating head injuries and blunt head injuries, which are far more common in the pediatric population. Patients with coexisting major injuries (abdominal, pelvic, femur, spinal cord, cardiac, and/or pulmonary trauma) rather than isolated head injury were also excluded from the study. In the evaluation of TBI-associated coagulopathy, these patients may have had hemorrhagic shock with different mechanisms associated with acute coagulopathy. AIS head scoring was based on the 2008 updated criteria. ${ }^{19}$ We chose these AIS scores to delineate a study population with isolated moderate to severe TBI and to investigate the relationship between isolated TBI and acute coagulopathy.
TABLE 1. Age-dependent normal coagulation values and TBI-associated coagulopathy values used in this study

\begin{tabular}{ccc}
\hline Lab Investigation & Normal Value & TBI-Associated Coagulopathy \\
\hline Platelet count & $\geq 150 \times 10^{3} / \mathrm{ml}$ & $<100 \times 10^{3} / \mathrm{ml}$ \\
\hline aPTT, sec & & \\
\hline Neonate & $29.5-44.8$ & $>44.8$ \\
\hline 1 mo to 1 yr & $35.1-46.3$ & $>46.3$ \\
\hline $2-5$ yrs & $33.6-43.8$ & $>43.8$ \\
\hline $6-10$ yrs & $31.8-43.7$ & $>43.7$ \\
\hline $11-16$ yrs & $33.9-46.1$ & $>46.1$ \\
\hline PT, sec & & $>16.4$ \\
\hline Neonate & $13.5-16.4$ & $>15.3$ \\
\hline 1 mo to 1 yr & $11.5-15.3$ & $>14.5$ \\
\hline $2-5$ yrs & $12.1-14.5$ & $>15.1$ \\
\hline $6-10$ yrs & $11.7-15.1$ & $>16.1$ \\
\hline $11-16$ yrs & $12.7-16.1$ & $>1.2$ \\
\hline INR & $\leq 1.2$ &
\end{tabular}

Patients were considered to have acute coagulopathy associated with isolated TBI based on findings of 1) no indication of preexisting congenital or acquired coagulopathy found in the patient history or on follow-up and 2) presence of coagulopathy demonstrated on initial blood investigations performed using samples obtained in the ED prior to initiation of any fluid, blood product, or pharmacological interventions (in both prehospital and ED settings).

\section{Methods and Measurements}

Coagulopathy was diagnosed based on findings of prothrombin time (PT), international normalized ratio (INR), or activated partial thromboplastin time (aPTT) above the range for age as defined by standardized institutional laboratory values for coagulation markers in the pediatric population or platelet counts of $100 \times 10^{3} / \mu$ l or less ${ }^{18}$ (Table 1 ).

Data for the following parameters were collected for the demographic status and injury category: age, sex, mode of injury, whether child abuse was suspected, and AIS head score. Other variables included ED triage parameters such as GCS score (lowest score recorded at the time of injury), heart rate, blood pressure, and pupil size. Vital signs were defined as abnormal if values were outside of normal ranges according to the Paediatric Canadian Triage and Acuity Scale. ${ }^{31}$ Data were collected for critical interventions such as ED resuscitation with crystalloid fluid, blood product administration, hyperosmolar therapy (hypertonic saline), and emergency endotracheal intubation. Neuroimaging data from the first head CT images performed postinjury in the ED and read by accredited radiologists were also recorded.

\section{Outcomes of Interest}

The outcomes of interest were in-hospital mortality and neurological outcome at 6 months postinjury assessed by using the pediatric version of the Glasgow Outcome Scale-Extended (GOS-E Peds). ${ }^{2}$ Functional assessment 
TABLE 2. GOS-E Peds categorization used to describe patient neurological outcomes at the 6-month follow-up

\begin{tabular}{|c|c|c|}
\hline $\begin{array}{c}\text { GOS-E } \\
\text { Peds Score }\end{array}$ & Component & Restriction(s) \\
\hline 1 & Death & - \\
\hline 2 & Vegetative & $\begin{array}{l}\text { Unable to obey simple commands or communicate (able to preinjury) } \\
\text { Younger patient unable to interact or react beyond reflexes }\end{array}$ \\
\hline 3 & $\begin{array}{l}\text { Lower severe } \\
\text { disability }\end{array}$ & $\begin{array}{l}\text { Requires daily assistance for activities of daily living (independent preinjury) } \\
\text { Younger patient dependent on caretaker more than expected based on age }\end{array}$ \\
\hline 4 & $\begin{array}{l}\text { Upper severe } \\
\text { disability }\end{array}$ & $\begin{array}{l}\text { Needs assistance but not frequent or full-time help (independent preinjury) } \\
\text { Younger patient does not need frequent help from caretaker to accomplish age-appropriate tasks } \\
\text { Unable to shop \& travel without assistance (able to preinjury) } \\
\text { Younger patient does not behave age appropriately outside home }\end{array}$ \\
\hline 5 & $\begin{array}{l}\text { Lower moderate } \\
\text { disability }\end{array}$ & $\begin{array}{l}\text { Able to work only in a sheltered workshop or noncompetitive job or in a school setting for severely impaired children or } \\
\text { tutored at home, or currently unable to work or go to school (if previously schooling) } \\
\text { Daily \& intolerable typical posttraumatic personality changes (quick temper, irritability, anxiety, aggressive acts, insen- } \\
\text { sitivity to others, mood swings, depression, age-inappropriate unreasonable or childish behavior) } \\
\text { Unable to or rarely participates in social \& leisure activities (able to preinjury) }\end{array}$ \\
\hline 6 & $\begin{array}{l}\text { Upper moderate } \\
\text { disability }\end{array}$ & $\begin{array}{l}\text { Significantly reduced work or school capacity } \\
\text { Frequent typical but tolerable posttraumatic personality changes }(\geq 1 / \mathrm{wk}) \\
<50 \% \text { of preinjury participation in social \& leisure activities }\end{array}$ \\
\hline 7 & $\begin{array}{l}\text { Lower good } \\
\text { recovery }\end{array}$ & $\begin{array}{l}\text { Age-appropriate functional capacity (home, work, or school) } \\
\text { Occasional (<1/wk) typical posttraumatic personality changes or nonspecific problems after head injury (headaches, diz- } \\
\text { ziness, tiredness, sensitivity to noise or light, slowness, memory failures, concentration problems, or other problems) } \\
\text { Participates a bit less ( } \geq 50 \% \text { of preinjury) in social \& leisure activities }\end{array}$ \\
\hline 8 & $\begin{array}{l}\text { Upper good } \\
\text { recovery }\end{array}$ & No problems related to injury that affect daily life (socially \& functionally) \\
\hline
\end{tabular}

Table based on current study data and adapted from Beers SR, Wisniewski SR, Garcia-Filion P, et al: Validity of a pediatric version of the Glasgow Outcome Scale-

Extended. J Neurotrauma 29:1126-1139, 2012.

at 6 months postinjury was performed by trained physiotherapists in our hospital. In this study we used the GOS-E Peds version that has been validated in children and correlates with long-term neurobehavioral outcomes. ${ }^{2}$ We used this categorization method to describe the neurological outcomes of the study patients at the 6-month follow-up (Table 2). In previously reported literature, GOS-E Peds scores have been categorized according to neurological outcomes of unfavorable for scores of 1-4 and favorable for scores of 5-8. ${ }^{30}$ However, we recognized that children with GOS-E Peds scores of 5-6 would still have significant functional deficits (Table 2). Therefore, for the regression analysis, we defined good neurological outcomes as GOS-E Peds scores of 7 to 8 (almost normal/normal function). To assess for any significant decrease in neurological outcome, we specifically looked at GOS-E Peds scores of $<7$ (death or survival with moderate to severe neurological disabilities) at 6 months postinjury.

\section{Statistical Analysis}

Data were entered on a Microsoft Excel spreadsheet (version 2016; Microsoft Corp.). IBM SPSS (version 22; IBM Corp.) was used to generate descriptive data for reporting. Values were reported as mean with standard deviation (SD) or median with interquartile range (IQR) for continuous variables (depending on normality) and as frequencies with percentages for categorical variables. Continuous variables were analyzed using a Student t-test (or its nonparametric equivalent) and dichotomous variables using a chi-square test or Fisher exact test as appropriate. We performed univariable and multivariable logistic regression for factors predictive of GOS-E Peds scores and associations with TBI-associated coagulopathy. In the multivariable regression analysis predicting for GOSE Peds $<7$ at 6 months, in addition to adjusting for the variable of interest (TBI-associated coagulopathy), we adjusted for the following: AIS head score, presence of hypotension, loss of gray-white differentiation, intraparenchymal bleeding, and midline shift. For the regression analysis predicting for TBI-associated coagulopathy, we adjusted for the following: demographic information such as age and sex, mechanism of injury, AIS head score, initial GCS, presence of hypotension, loss of gray-white differentiation, intraparenchymal bleeding, and midline shift. The variables were chosen based on their significance on univariable regression analysis and on the literature.

\section{Ethical Approval}

The study protocol was approved by our institution's committee on human research (CIRB 2016/3071), with waiver of informed consent.

\section{Results}

There were 155 patients included in the study, who comprised the complete cohort of pediatric patients with isolated moderate to severe TBI during the study period. Follow-up at 6 months was complete for this cohort. 
TABLE 3. Clinical characteristics and outcomes of pediatric patients with isolated moderate to severe blunt head injury

\begin{tabular}{|c|c|c|c|c|}
\hline Parameter & $\begin{array}{c}\text { Total } \\
(n=155)\end{array}$ & $\begin{array}{c}\text { TBI-Associated } \\
\text { Coagulopathy }(n=33)\end{array}$ & $\begin{array}{c}\text { No TBI-Associated } \\
\text { Coagulopathy }(n=122)\end{array}$ & $\begin{array}{c}\mathrm{p} \\
\text { Value }\end{array}$ \\
\hline \multicolumn{5}{|l|}{ Epidemiology } \\
\hline Sex & & & & 0.537 \\
\hline Male & $102(65.8)$ & $20(60.6)$ & $82(67.2)$ & \\
\hline Female & $53(34.2)$ & $13(39.4)$ & $40(32.8)$ & \\
\hline Mean age, yrs & $7.03 \pm 5.08$ & $6.82 \pm 4.72$ & $7.09 \pm 5.19$ & 0.937 \\
\hline Mode of injury & & & & 0.264 \\
\hline Fall & $101(65.2)$ & $20(60.6)$ & $81(66.4)$ & \\
\hline MVC & $42(27.1)$ & $12(36.4)$ & $30(24.6)$ & \\
\hline $\mathrm{NAI}$ & $12(7.7)$ & $1(3.0)$ & $11(9.0)$ & \\
\hline AIS head score & $4(3-4)$ & $4(4-5)$ & $4(3-4)$ & $<0.001$ \\
\hline \multicolumn{5}{|l|}{ ED clinical signs } \\
\hline Hypotension at ED & $23(14.8)$ & $21(63.6)$ & $2(1.6)$ & $<0.001$ \\
\hline Initial GCS score & $13(13-14)$ & $12(7-13)$ & $14(13-14)$ & $<0.001$ \\
\hline Initial GCS score $\leq 8$ & $14(9.0)$ & $10(30.3)$ & $4(3.3)$ & $<0.001$ \\
\hline Anisocoria & $6(3.9)$ & $6(18.2)$ & $0(0)$ & $<0.001$ \\
\hline \multicolumn{5}{|l|}{ Critical interventions } \\
\hline Emergency intubation performed in ED & $16(10.3)$ & $12(36.4)$ & $4(3.3)$ & $<0.001$ \\
\hline Crystalloid resuscitation in ED & $26(16.8)$ & $22(66.7)$ & $4(3.3)$ & $<0.001$ \\
\hline Blood products administered in ED & $9(5.8)$ & $8(24.2)$ & $1(0.8)$ & $<0.001$ \\
\hline Hyperosmolar therapy/hypertonic saline administered in ED & $20(12.9)$ & $13(39.4)$ & $7(5.7)$ & $<0.001$ \\
\hline Emergency neurosurgical intervention & $45(29.0)$ & $21(63.6)$ & $24(19.7)$ & $<0.001$ \\
\hline Repeat brain CT after ICU admission & $34(21.9)$ & $16(48.5)$ & $18(14.8)$ & $<0.001$ \\
\hline \multicolumn{5}{|l|}{ Clinical outcome } \\
\hline Death after head trauma & $9(5.8)$ & $8(24.2)$ & $1(0.8)$ & $<0.001$ \\
\hline GOS-E Peds score & $8(7-8)$ & $6(4-7)$ & $8(7-8)$ & $<0.001$ \\
\hline Favorable neurological recovery_GOS-E Peds score 5-8 & $146(94.2)$ & $25(75.6)$ & $121(99.2)$ & $<0.001$ \\
\hline Good neurological recovery-GOS-E Peds score 7-8 & $122(78.7)$ & $12(36.4)$ & $110(90.2)$ & $<0.001$ \\
\hline
\end{tabular}

Values are presented as number of patients (\%), median (IQR), or mean \pm SD unless otherwise indicated. Boldface type indicates statistical significance.

The mean (SD) age of the study group was 7.03 (5.0) years. The mechanism of injury was predominantly fall, in 101 children $(65.16 \%)$, followed by motor vehicle collision (MVC) in 42 children (27.1\%) and suspected child abuse (nonaccidental injury [NAI]) in 12 children (7.74\%; Table 3). The median AIS head score was 4. The median initial presenting GCS score was 13 (IQR 12-15).

In $33(21.3 \%)$ pediatric patients with isolated blunt head injury, coagulopathy was observed during the initial blood investigations done in the ED. There were no statistical differences in age, sex, or mechanism of injury between the pediatric patients who had TBI-associated coagulopathy and those who did not. Patients with TBI-associated coagulopathy tended to have more severe head injury ( $\mathrm{p}<$ $0.001)$ and lower initial presenting GCS score $(\mathrm{p}<0.001$; Table 3).

The overall mortality rate was $5.8 \%$ (9 patients). Eight of the 9 patients who died had TBI-associated coagulopathy ( $\mathrm{p}<0.001)$. The median GOS-E Peds score for children with TBI-associated coagulopathy was 6 (upper moderate disability, IQR 4-7), compared with 8 (upper good recovery, IQR 7-8) for those without coagulopathy ( $<$
0.001). Patients with TBI-associated coagulopathy were more likely to have unfavorable neurological outcomes at 6 months $(\mathrm{p}<0.001)$ in our univariate analyses. In our cohort, after adjusting for confounders, the only 2 factors predictive for GOS-E Peds scores of $<7$ at 6 months were initial GCS score ( $\mathrm{p}=0.001$, adjusted OR $0.61,95 \%$ CI $0.56-0.82)$ and TBI-associated coagulopathy $(\mathrm{p}=0.02$, adjusted OR 6.07, 95\% CI 1.32-27.83; Table 4).

TBI-associated coagulopathy was also associated with ED intubation, crystalloid resuscitation, blood product administration, hyperosmolar therapy with hypertonic saline, repeat neuroimaging after ICU admission, and neurosurgical intervention (all $\mathrm{p}<0.001$; Table 3 ).

Hypotension at triage was noted in $25 \%$ of our patients with isolated moderate to severe blunt head injury. Patients who had hypotension on arrival had a higher odds of having acute coagulopathy ( $\mathrm{p}<0.001$, OR $115.5,95 \%$ CI 23.8-558.6). Among patients who had TBI-associated coagulopathy, hypotension in the ED was an independent risk predictor. All 9 patients who eventually died had hypotension in the ED.

Anisocoria was noted in 6 patients in the ED. All 6 
TABLE 4. Multivariate analysis for predictors of GOS-E Peds score $<7$ at 6 months

\begin{tabular}{lcc}
\hline \multicolumn{1}{c}{ Clinical Variable } & $p$ Value & Adjusted OR (95\% Cl) \\
\hline Age, yrs & 0.360 & $1.06(0.94-1.18)$ \\
\hline Initial GCS score & $\mathbf{0 . 0 0 1}$ & $\mathbf{0 . 6 1}(\mathbf{0 . 5 6 - 0 . 8 2 )}$ \\
\hline TBI-associated coagulopathy & $\mathbf{0 . 0 2 0}$ & $\mathbf{6 . 0 7}(\mathbf{1 . 3 2 - 2 7 . 8 3 )}$ \\
\hline Hypotension at ED triage & 0.968 & $0.96(0.12-7.49)$ \\
\hline Cerebral edema/loss of gray-white differentiation & 0.169 & $3.03(0.62-14.79)$ \\
\hline Intraparenchymal bleed & 0.196 & $2.36(0.64-8.64)$ \\
\hline Midline shift & 0.086 & $6.30(0.77-51.63)$ \\
\hline
\end{tabular}

Boldface type indicates statistical significance.

patients with anisocoria had TBI-associated coagulopathy $(p<0.001)$ and hypotension in the ED, and all of these patients died.

All 155 patients underwent brain CT studies and there were no normal reports for this cohort. The most common brain CT finding was skull fracture (65.8\% of patients), and the most common intracranial hemorrhage was subdural hematoma (42.5\%) (Table 5). More severe findings included evidence of midline shift (12.4\% of patients), cerebral edema/loss of gray-white differentiation (10.6\%), and diffuse axonal injury (6.2\%). The presence of early coagulopathy was significantly associated with imaging findings of subarachnoid bleed, intraparenchymal bleed, midline shift, and cerebral edema/loss of gray-white differentiation (Table 5). However, these findings were not significant after adjusting for confounders (Table 6).

In our cohort, we found AIS head score $(\mathrm{p}=0.048)$ and hypotension observed at triage $(\mathrm{p}=0.001)$ to be the only 2 factors independently associated with TBI-associated coagulopathy after adjusting for confounders (Table 6).

\section{Discussion}

In this study, we documented the incidence of acute coagulopathy among children with isolated moderate to severe blunt head injuries. We found that the presence of acute coagulopathy was independently predictive of
GOS-E Peds scores of $<7$ (death, moderate to severe neurological disability) at 6 months postinjury.

The mean age ( 7.03 years) of the patients in our study group is lower than that reported in previous studies.1,28 The predominant mechanism of injury in our study group was falls, which differs from the findings of other epidemiological studies in which MVC was the most common mechanism. ${ }^{5}$ These differences could be due to the different pediatric trauma landscape in densely populated Singapore, whereby most of the population resides in high-rise buildings and there are relatively strict road traffic laws.

We found that coagulopathy is common among children with isolated moderate to severe blunt TBI (21.3\%). This finding is consistent with earlier reported incidences of coagulopathy ranging between $10 \%$ and $97 \%$ in combined pediatric and adult populations after various types of isolated TBI. . $^{70,25,28}$

Based on our review of patient data, we excluded any patients who had prehospital or ED fluid administration to ensure that any deranged coagulopathy observed from initial ED blood investigations was likely primary. The coagulopathy profile is not confounded by hypothermia in Singapore due to the equatorial effect.

The overall mortality rate reported in our study was low (5.8\%) compared with mortality rates ranging from $25 \%$ to $35 \%$ reported in other studies. ${ }^{6,29}$ Our study findings were consistent with those of both adult and pediatric

TABLE 5. Associations of neuroimaging findings of the first postinjury head CT with TBI-associated coagulopathy

\begin{tabular}{|c|c|c|c|c|}
\hline Neuroimaging Finding & Total $^{*}(n=155)$ & TBI-Associated Coagulopathy $(n=33)$ & No TBI-Associated Coagulopathy $(n=122)$ & $\mathrm{p}$ Value \\
\hline Skull fracture & $102(65.8)$ & $24(72.7)$ & $78(63.9)$ & 0.412 \\
\hline Extradural hematoma & $54(34.8)$ & $14(42.4)$ & $40(32.8)$ & 0.311 \\
\hline Subdural hematoma & $66(42.5)$ & $13(39.4)$ & $53(43.4)$ & 0.697 \\
\hline Subarachnoid bleed & $4(2.6)$ & $3(9.1)$ & $1(0.8)$ & 0.018 \\
\hline Intraventricular bleed & $5(3.2)$ & $3(9.1)$ & $2(1.6)$ & 0.065 \\
\hline Intraparenchymal bleed & $38(24.5)$ & $18(54.5)$ & $20(16.4)$ & $<0.001$ \\
\hline Diffuse axonal injury & $11(7)$ & $4(12.1)$ & $7(5.7)$ & 0.249 \\
\hline $\begin{array}{l}\text { Cerebral edema/loss of } \\
\text { gray-white differentiation }\end{array}$ & $19(12.3)$ & $10(30.3)$ & $9(7.4)$ & 0.001 \\
\hline Midline shift & $13(8.3)$ & $10(30.3)$ & $3(2.5)$ & $<0.001$ \\
\hline
\end{tabular}

Values are presented as number of patients (\%) unless otherwise indicated. Boldface type indicates statistical significance.

* All 155 patients had at least one abnormal neuroimaging finding. 
TABLE 6. Multivariate logistic regression table for clinical risk factors associated with TBI-associated coagulopathy

\begin{tabular}{lcc}
\hline \multicolumn{1}{c}{ Clinical Variable } & p Value & Adjusted OR $(95 \% \mathrm{Cl})$ \\
\hline Male sex & 0.945 & $0.96(0.28-3.23)$ \\
\hline Age, yrs & 0.722 & $1.02(0.91-1.15)$ \\
\hline Mode of injury & & \\
\hline Fall from height & - & Ref \\
\hline MVC & 0.521 & $0.521(0.12-2.27)$ \\
\hline NAI & 0.599 & $0.52(0.05-5.89)$ \\
\hline AIS head score & 0.048 & $3.22(1.01-10.30)$ \\
\hline Initial GCS score & 0.094 & $1.40(0.95-2.07$ \\
\hline Hypotension at ED triage & $\mathbf{0 . 0 0 1}$ & $281.77(11.38-6979.08)$ \\
\hline $\begin{array}{l}\text { Cerebral edema/loss of } \\
\text { gray-white differentiation }\end{array}$ & 0.736 & $0.69(0.82-5.86)$ \\
\hline Intraparenchymal hematoma & 0.513 & $1.63(0.38-7.06)$ \\
\hline Midline shift & 0.580 & $2.05(0.16-26.13)$ \\
\hline
\end{tabular}

Boldface type indicates statistical significance.

studies demonstrating that trauma-induced coagulopathy is associated with increased disability, as measured by GOS-E Peds and mortality.,17,23,25,26 Many studies define unfavorable neurological outcome as a GOS-E Peds score of 1 to 4, which includes death. In the analysis of neurological outcomes for survivors, this would be a potential confounder, especially if TBI-associated coagulopathy was already a known predictor of mortality. Most studies on neurological sequelae refer to moderate neurological disability as a "favorable" outcome. However, pediatric patients with lower and upper moderate disability still have significant functional and social restrictions (Table 2). ${ }^{2}$ The absence of TBI-associated coagulopathy was strongly associated with good neurological recovery (GOS-E Peds score 7-8, p < 0.001). After adjusting for confounders, in addition to initial GCS, TBI-associated coagulopathy was found to be independently associated with GOS-E Peds scores of $<7$ (death or survival with poor or moderate neurological recovery) at 6 months postinjury (Table 4).

Acute coagulopathy is a frequent complication of pediatric abusive head trauma and it is strongly associated with the presence of parenchymal brain damage. ${ }^{4,14,20}$ However, we were not able to find a similar association of NAI with TBI-associated coagulopathy in our cohort with NAI ( $p$ $=0.69$ ). This result could be due to the small numbers of patients with abusive head trauma $(n=12)$ during the period of study.

Low GCS scores at presentation $(<8)$ have been shown in earlier studies to be a risk factor for development of TBI coagulopathy. ${ }^{3,21}$ While median GCS score and GCS score $\leq 8$ were found to have statistically significant associations with TBI-associated coagulopathy on univariate analysis $(p<0.001)$, they were not identified as a risk factor in the regression analysis (Table 6). This result could be attributable to our relatively small sample size of only 155 . GCS and AIS head scores appeared to confound each other, likely due to the strong correlation between these 2 factors.

It also remains to be seen if TBI-associated coagulopathy is a marker of head injury severity and is prog- nosticative of clinical outcomes or a target for therapeutic reversal to prevent or manage progression of intracranial hemorrhage. It is also unknown if early correction of TBI-associated coagulopathy (for example, using blood products and/or tranexamic acid) would affect mortality and neurological outcomes. The interaction and effects of vasoactive agents (especially catecholamines) and fluid resuscitation on coagulation profiles, and optimal blood pressure in pediatric populations with isolated severe head injuries are also areas to be studied. ${ }^{12,15,27}$ These investigations would require large prospective studies, possibly as part of a multicenter study or pediatric research network, given the relatively small numbers of severe head injuries in the pediatric population.

\section{Limitations}

The present study should be interpreted based on its limitations, primarily those that are inherent with a single-center, retrospective analysis. The data collected were, however, actively captured as part of our hospital's head injury and trauma surveillance. We used age-appropriate hospital-based norms to define coagulopathy, which may differ between institutions. It would also have been useful to have been able to document the amount of time that elapsed between the initial injury and the laboratory assessment for coagulopathy, but these data were not consistently available from patient records.

To elucidate the relationship between coagulation profiles, platelets, and isolated blunt head injury unaffected by prior interventions, our strict inclusion and exclusion criteria contributed to a relatively small sample size. However, we had noted that based on the limited pediatric publications on this topic, most studies had similar if not smaller numbers.

\section{Conclusions}

In our study of a pediatric population with isolated moderate to severe blunt head injury, there was demonstrated evidence of TBI-associated coagulopathy in $21.3 \%$ of patients during the initial blood investigations performed in the ED. TBI-associated coagulopathy was independently associated with GOS-E Peds scores of $<7$ (death, moderate to severe neurological disability) at 6 months postinjury ( $\mathrm{p}=0.02$, adjusted OR 6.07, 95\% CI 1.32-27.83). Larger prospective studies should be done to investigate whether TBI-associated coagulopathy can be used to prognosticate these critical clinical outcomes.

\section{References}

1. Affonseca CA, Carvalho LFA, Guerra SD, Ferreira AR, Goulart EMA: Coagulation disorder in children and adolescents with moderate to severe traumatic brain injury. J Pediatr (Rio J) 83:274-282, 2007

2. Beers SR, Wisniewski SR, Garcia-Filion P, Tian Y, Hahner $\mathrm{T}$, Berger RP, et al: Validity of a pediatric version of the Glasgow Outcome Scale-Extended. J Neurotrauma 29:1126-1139, 2012

3. Bruins BB, Kilbaugh TJ, Friess SH: Coagulopathy after pediatric traumatic brain injury: association or causality? Pediatr Crit Care Med 13:491-492, 2012

4. Chang R, Cardenas JC, Wade CE, Holcomb JB: Advances in 
the understanding of trauma-induced coagulopathy. Blood 128:1043-1049, 2016

5. Chen C, Peng J, Sribnick EA, Zhu M, Xiang H: Trend of age-adjusted rates of pediatric traumatic brain injury in U.S. emergency departments from 2006 to 2013. Int J Environ Res Public Health 15:E1171, 2018

6. Chhabra G, Sharma S, Subramanian A, Agrawal D, Sinha S, Mukhopadhyay AK: Coagulopathy as prognostic marker in acute traumatic brain injury. J Emerg Trauma Shock 6:180-185, 2013

7. Cohen MJ, Brohi K, Ganter MT, Manley GT, Mackersie RC, Pittet JF: Early coagulopathy after traumatic brain injury: the role of hypoperfusion and the protein $\mathrm{C}$ pathway. J Trauma 63:1254-1262, 2007

8. Dewan MC, Mummareddy N, Wellons JC III, Bonfield CM: Epidemiology of global pediatric traumatic brain injury: qualitative review. World Neurosurg 91:497-509.e1, 2016

9. Di Battista AP, Rizoli SB, Lejnieks B, Min A, Shiu MY, Peng HT, et al: Sympathoadrenal activation is associated with acute traumatic coagulopathy and endotheliopathy in isolated brain injury. Shock 46 (3 Suppl 1):96-103, 2016

10. Doshi BS, Meeks SL, Hendrickson JE, Reisner A, Leong T, Winkler AM, et al: Coagulopathy predicts mortality in pediatric patients with traumatic brain injury. Blood 124:2891, 2014

11. Folkerson LE, Sloan D, Davis E, Kitagawa RS, Cotton BA, Holcomb JB, et al: Coagulopathy as a predictor of mortality after penetrating traumatic brain injury. Am J Emerg Med 36:38-42, 2018

12. Gardner A, Poehling KA, Miller CD, Tooze JA, Petty J: Isolated head injury is a cause of shock in pediatric trauma patients. Pediatr Emerg Care 29:879-883, 2013

13. Harhangi BS, Kompanje EJO, Leebeek FWG, Maas AIR: Coagulation disorders after traumatic brain injury. Acta Neurochir (Wien) 150:165-175, 2008

14. Hymel KP, Abshire TC, Luckey DW, Jenny C: Coagulopathy in pediatric abusive head trauma. Pediatrics 99:371-375, 1997

15. Johnson MA, Borgman MA, Cannon JW, Kuppermann N, Neff LP: Severely elevated blood pressure and early mortality in children with traumatic brain injuries: the neglected end of the spectrum. West J Emerg Med 19:452-459, 2018

16. Keenan HT, Bratton SL: Epidemiology and outcomes of pediatric traumatic brain injury. Dev Neurosci 28:256-263, 2006

17. Königs M, Engenhorst PJ, Oosterlaan J: Intelligence after traumatic brain injury: meta-analysis of outcomes and prognosis. Eur J Neurol 23:21-29, 2016

18. Liu J, Tian HL: Relationship between trauma-induced coagulopathy and progressive hemorrhagic injury in patients with traumatic brain injury. Chin J Traumatol 19:172-175, 2016

19. Loftis KL, Price J, Gillich PJ: Evolution of the Abbreviated Injury Scale: 1990-2015. Traffic Inj Prev 19 (sup2):S109S113, 2018

20. Miner ME, Kaufman HH, Graham SH, Haar FH, Gildenberg PL: Disseminated intravascular coagulation fibrinolytic syndrome following head injury in children: frequency and prognostic implications. J Pediatr 100:687-691, 1982

21. Peiniger S, Nienaber U, Lefering R, Braun M, Wafaisade A, Borgman MA, et al: Glasgow Coma Scale as a predictor for hemocoagulative disorders after blunt pediatric traumatic brain injury. Pediatr Crit Care Med 13:455-460, 2012

22. Podolsky-Gondim GG, Furlanetti LL, Viana DC, Ballestero MFM, de Oliveira RS: The role of coagulopathy on clinical outcome following traumatic brain injury in children: analysis of 66 consecutive cases in a single center institution. Childs Nerv Syst 34:2455-2461, 2018

23. Recla M, Bardoni A, Galbiati S, Pastore V, Dominici C, Tavano $\mathrm{A}$, et al: Cognitive and adaptive functioning after severe TBI in school-aged children. Brain Inj 27:862-871, 2013

24. Santiago LA, Oh BC, Dash PK, Holcomb JB, Wade CE: A clinical comparison of penetrating and blunt traumatic brain injuries. Brain Inj 26:107-125, 2012.

25. Stolla M, Zhang F, Meyer MR, Zhang J, Dong JF: Current state of transfusion in traumatic brain injury and associated coagulopathy. Transfusion 59 (S2): 1522-1528, 2019

26. Strumwasser A, Speer AL, Inaba K, Branco BC, Upperman JS, Ford HR, et al: The impact of acute coagulopathy on mortality in pediatric trauma patients. J Trauma Acute Care Surg 81:312-318, 2016

27. Suttipongkaset $P$, Chaikittisilpa N, Vavilala MS, Lele AV, Watanitanon A, Chandee T, et al: Blood pressure thresholds and mortality in pediatric traumatic brain injury. Pediatrics 142:e20180594, 2018

28. Talving P, Lustenberger T, Lam L, Inaba K, Mohseni S, Plurad D, et al: Coagulopathy after isolated severe traumatic brain injury in children. J Trauma 71:1205-1210, 2011

29. Verchère J, Blanot $S$, Vergnaud E, Vecchione A, Zerah M, Meyer PG: Mortality in severe traumatic brain injury. Lancet Neurol 12:426-427, 2013

30. Weir J, Steyerberg EW, Butcher I, Lu J, Lingsma HF, McHugh GS, et al: Does the extended Glasgow Outcome Scale add value to the conventional Glasgow Outcome Scale? J Neurotrauma 29:53-58, 2012

31. Yates MT, Ishikawa T, Schneeberg A, Brussoni M: Pediatric Canadian Triage and Acuity Scale (PaedsCTAS) as a measure of injury severity. Int J Environ Res Public Health 13:E659, 2016

32. Zhang D, Gong S, Jin H, Wang J, Sheng P, Zou W, et al: Coagulation parameters and risk of progressive hemorrhagic injury after traumatic brain injury: a systematic review and meta-analysis. Biomed Res Int 2015:261825, 2015

33. Zhang J, Jiang R, Liu L, Watkins T, Zhang F, Dong JF: Traumatic brain injury-associated coagulopathy. J Neurotrauma 29:2597-2605, 2012

\section{Disclosures}

The authors report no conflict of interest concerning the materials or methods used in this study or the findings specified in this paper.

\section{Author Contributions}

Conception and design: Ong. Acquisition of data: James, Shetty. Analysis and interpretation of data: Ong, James, Chong. Drafting the article: Ong, James. Critically revising the article: all authors. Reviewed submitted version of manuscript: all authors. Approved the final version of the manuscript on behalf of all authors: Ong. Statistical analysis: Chong. Administrative/technical/material support: Ong, Chong. Study supervision: Ong.

\section{Correspondence}

Gene Y. Ong: Children's Emergency, KK Women's and Children's Hospital, Singapore.geneong@yahoo.com. 